\title{
Influence of contact points of helicopter skid landing gears on ground resonance stability
}

\author{
Reinhard Lojewski ${ }^{1} \cdot$ Christoph Kessler $^{1} \cdot$ Rainer Bartels $^{1}$
}

Received: 25 November 2019 / Revised: 6 March 2020 / Accepted: 8 April 2020 / Published online: 23 April 2020

(c) The Author(s) 2020

\begin{abstract}
Soft-in-plane rotor systems are susceptible to a self-induced vibration phenomenon called ground resonance. This dynamic instability results from lag motions of the rotor blades coupling with airframe degrees of freedom, while the helicopter is in ground contact. As an addition to slope landing studies in the past and investigations of non-linear landing gear effects, this work focuses on a systematic study of partial skid contact. A ground resonance test environment was created. It encompasses 3D helicopter models with flexible landing gear models using direct finite-element models and applying modal reduction to embed CAD-derived landing gear models. Both approaches are used in a multibody dynamics simulation. The models showed acceptable results for the simulation of non-linear dynamic behaviour including typical non-linear effects like limit cycles. Special focus is given to different methods of contact simulation, using 3D spring-damper elements and polygonal contact elements for multi-directional contacts. The simulations showed two counteracting effects for partial ground contact and time-variant contact conditions. On one hand, the reduction of restoring forces in partial ground contact should lead to more unstable conditions. On the other hand, energy dissipation shows a larger influence on the system stability behaviour after a sudden disturbance. This effect is of high interest for soft, partial landing conditions.
\end{abstract}

Keywords Ground resonance · Ground contact · Landing gear · Instability

\section{Introduction}

The lead-lag motion of the rotor blade in the rotating system can be transformed into the non-rotating reference frame. This leads to a progressive $\left|\Omega+\omega_{\zeta}\right|$ and a regressive component $\left|\Omega-\omega_{\zeta}\right|$ of the lead-lag eigenfrequency, with $\Omega$ as the rotation frequency and $\omega_{\zeta}$ as the lead-lag frequency in the rotating system [1]. Critical for ground resonance is the regressive lead-lag motion, since its frequency can be in the same magnitude as some airframe motions. The ground resonance has a low-frequency characteristic usually located in a frequency range of less than $5 \mathrm{~Hz}$ [2]. The dynamic

Reinhard Lojewski

Reinhard.Lojewski@dlr.de

Christoph Kessler

Christoph.Kessler@dlr.de

Rainer Bartels

Rainer.Bartels@dlr.de

1 Department Helicopters, DLR German Aerospace Center, Institute of Flight Systems, Lilienthalplatz 7, 38108 Brunswick, Germany behaviour of the helicopter airframe in this frequency range is largely determined by the landing gear elasticity and its contact to the ground [1].

The first analysis of the ground resonance problem was performed by Robert Coleman and Arnold Feingold [3]. Their work was extended by Donham [4], Cardinale, and Sachs. They considered ground resonance and the related phenomenon in airborne conditions called air resonance. Especially for hingeless and bearingless rotors, Ormiston [5] and Hodges [6] made major contributions. Researchers like Price tried to derive stability criteria for the design of helicopters. While these early mainly focused on simplified or analytical models, modern studies for rotor-fuselage coupling [7, 8] and ground resonance [9] make use of finiteelement-based models or finite-element models embedded in a multibody simulation framework $[10,11]$.

There are several analysis methods to determine the helicopter's stability in regard to ground resonance. Assuming periodic solutions of the rotor system, stability analysis can be performed using Floquet Theory as presented in $[12,13]$. By neglecting periodicity, a constant coefficient approximation can be used [14]. These methods, however, are less 
suitable for finite-element models or test data. For full nonlinear systems methods, the application of Lyapunov Characteristic Exponents [15] or bifurcation analysis methods as given in [16] was derived.

While there are a number studies describing non-linear dampers in wheeled landing gears like, there has been significantly less attention on stability analysis of helicopters in exotic, operational landing conditions. For helicopters with wheels, Sansal, Kargin, and Zengin implemented a generic ground model in a MATLAB-Simulink environment [17] in which they considered trim calculations for landings on angled surfaces. For skid landing gears, Dieterich and Houg studied the contact conditions for slope landings [2]. In both papers, contact was modelled using non-linear friction laws and stick-slip friction effects to model different terrains.

In addition to their work, this paper presents a ground resonance simulation framework for 3D multi-point contact. This is done to represent partial ground contact. This encompasses landings in rocky terrain, in pits, or on guardrails, for example during rescue operations. The models and simulation results in this paper focus on helicopters with skid landing gears as they are in general used for light and medium weight helicopters. Due to smaller nacelle inertias, these helicopters are also more susceptible to self-induced vibrations phenomena. In comparison to helicopters with wheels, they usually do not have additional landing gear dampers. The landing gears dynamic behaviour is mainly determined by the structural stiffness and damping as well as its contact to the ground.

Full skid contact raises the eigenfrequencies of the helicopter fuselage, increasing the stability margin for ground resonance [18]. For operative landing scenarios, full contact conditions cannot be guaranteed. In rocky terrain, the skids may only have partial contact to the ground, leading to fuselage eigenfrequencies closer to the regressive lead-lag eigenfrequency. Additionally, different friction and damping effects in comparison to full contact scenarios can also influence the dynamic stability of the helicopter. If ground resonance occurs, immediate take-off or abortion of the landing will stop the oscillation.

\section{Preliminary studies}

As a first step to understand non-linear effects during partial ground contact, a simplified ground resonance model for helicopters was created as sketched in Fig. 1. The use of the multibody-software SIMPACK allows the straightforward definition of multibody-systems and the linear or non-linear dynamic simulation of finite-element structures and modal reduced flexible bodies. Non-linear system behaviour is expected due to contact conditions [19].

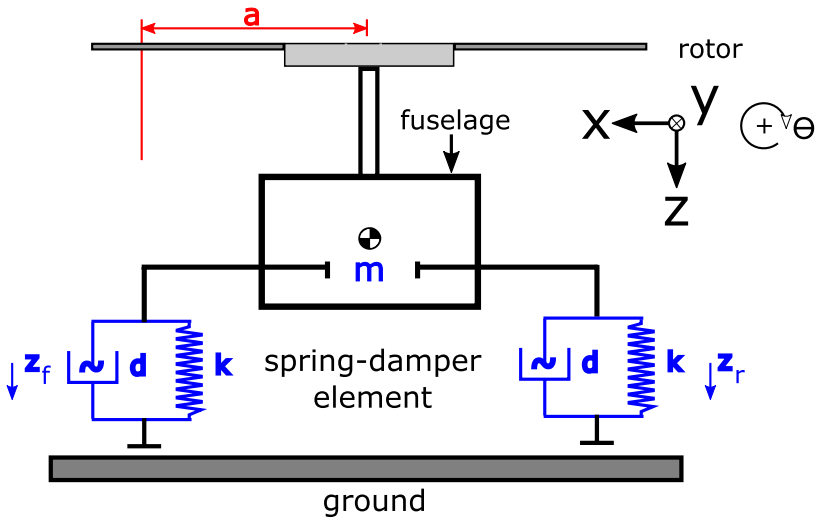

Fig. 1 Setup of simplified ground resonance model

The model consist of a four-bladed rotor with rigid blades, which are attached to a hub by spring-damper elements.

Additionally, two non-linear spring-damper elements are used to represent the landing gear. They are placed at the front (index f) and rear (index r) of the rigid airframe, allowing the helicopter to pitch in the longitudinal direction of the fuselage. Other movement directions are constrained.

The landing gear stiffness was chosen as $k=370,000 \mathrm{~kg} / \mathrm{s}^{2}$, the damper constant as $d=1,100,000 \mathrm{~kg} / \mathrm{s}$, and the airframe mass as $m=1906.4 \mathrm{~kg}$ to resemble a Bo105 helicopter [20]. The deflection at the front element is described by $z_{\mathrm{f}}=z-a \Theta$, with $a$ being the horizontal distance to the airframe centre of gravity and $\Theta$ as the pitch angle of the airframe relative to the ground. The rear deflection is given by $z_{\mathrm{r}}=z+a \Theta$.

For a linear model, the differential equations can be written as:

$m \ddot{z}+2 d \dot{z}+2 k z=m g-F_{\text {thrust }}$

$I_{\theta} \ddot{\theta}+2 d a^{2} \dot{\theta}+2 k a^{2} \theta=Q h$

with the mass moment of inertia $I_{\theta}$ and the rotor thrust $F_{\text {thrust }}$. The excitation of the model is later applied by the shear force $Q$ which attacks at the rotor in the distance $h$ of the fuselage centre of gravity.

Assuming the spring-damper system is not attached to the ground, it is unable to transfer tension forces. The differential equations become non-linear, as described in [21]. To account for this behaviour, the non-linear spring-damper forces are derived as presented in [20]. This simplified model of spring-damper forces was validated against the experimental data in [26]:

$F_{\mathrm{f}, \mathrm{r}}=\frac{1}{2} k\left(z_{\mathrm{f}, \mathrm{r}}+\sqrt{z_{\mathrm{f}, \mathrm{r}}^{2}+\epsilon^{2}}\right) \cdot\left(1+b \dot{z}_{\mathrm{f}, \mathrm{r}}\right)$. 
In Eq. (12), the factor $\epsilon$ denotes a small parameter for smoothing of the damping curve. The dependence of the spring-damper force on the displacement is given by the term $z_{\mathrm{f}, \mathrm{r}}+\sqrt{z_{\mathrm{f}, \mathrm{r}}^{2}+\epsilon^{2}}$, approximating a unilateral contact. The parameter $b$ describes the non-linear damping behaviour:

$b=\frac{2 d}{k\left(\frac{m g}{2 k}+\sqrt{\frac{m g}{2 k}}^{2}+\epsilon^{2}\right)}$.

Here, g denotes gravitational acceleration of $9.81 \mathrm{~m} / \mathrm{s}^{2}$.

The model allows to verify the typical analysis method using multi-blade coordinate transformation [22]. Additionally, the model was used to test the scripts for the analysis methods used for the study of varying contact areas. This encompasses time simulations with sweeps over the rotor rotation frequency, the monitoring of marker movements at the airframe, hub, and landing gear as well as a first test for the determination of vibration decay ratios. These analysis methods are later used for more complex models and are described in detail in Sect. 3. Additionally, the model was used to reproduce the results of previous analytical studies [20] with the multibody simulation tool SIMPACK. First structural analysis confirmed that the model shows nonlinear behaviour like the appearance of periodic solutions in time simulations for partial ground contact.

Preliminary time integrations showed that the variation of the spring-damper deflection height has a significant influence on the dynamic behaviour of the helicopter model, as described by [20]. This indicates the significant influence of partial ground contact on ground resonance stability. Variations of this model were used to test contact modelling options in SIMPACK. This preliminary work motivates further and more advanced studies concerning more usual ground contacts. These landing condition will be denoted 'operational landing conditions' in the following.

\section{Analysis}

To expand the investigation of landing gear-ground interaction, the system's dynamic response to contact point and contact area variation is studied. A flexible landing gear model described in Sect. 3.2 is chosen for this task. It is attached to a rigid fuselage.

The contact forces are modelled using SIMPACK force elements. Figure 2 depicts the contact configurations studied in this work. These conditions, originally defined by Donham [4], serve as a first set of operational landing conditions. They are intended to resemble real-landing conditions on rocky terrain, in pits, or on guardrails. Furthermore, in case of local contact, as shown in the top right corner of Fig. 2,

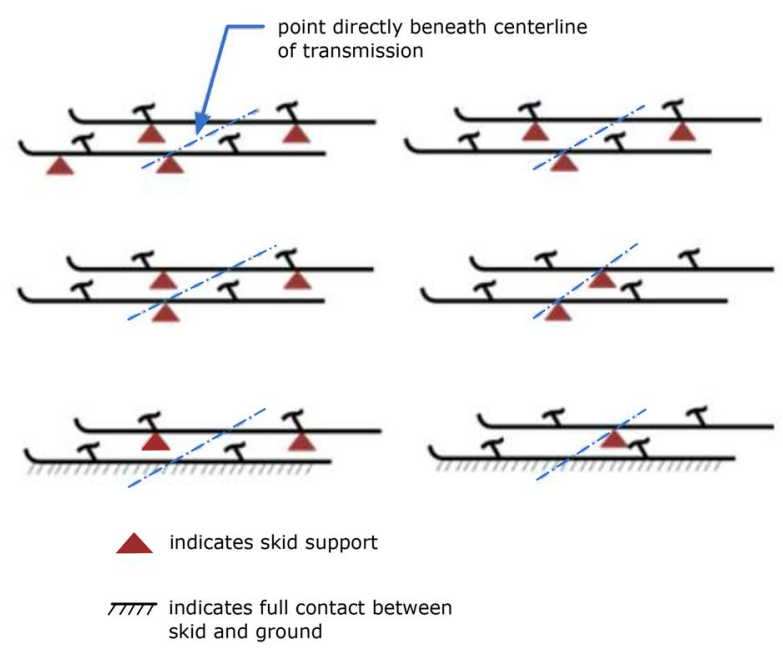

Fig. 2 Donham contact cases [4]

the position of the contact is varied along the skid. Typically in stability analysis for numerical models of landing gears, the models are linearised with respect to a working point. This neglects the non-linear effects due to partial contact or soft ground conditions. Therefore, the analysis method in this paper follows the approach given in [2]. To account for non-linear behaviour, time simulations are conducted and the time-history signals of sensors at the landing gear, airframe, and hub are monitored. In case of instability, the divergence of this signals can give basic information on the involved, coupled modes. The model has limits to its possible physical behaviour due to gravity enforcing ground contact and the ground itself, which restricts its motion. These physical constraints imply the system signal behaviour. In full contact, the system time response resembles the one of the classical ground model. The other extreme represents no contact at all with airborne condition. The study of the time signal within these boundaries, therefore, resembles a bounded-input, bounded-output (BIBO) stability analysis.

This approach is suited for contact or friction, but does not account for the full set of modes. For every mode of interest, a corresponding set of sensors has to be selected. The dynamic behaviour of each configuration is studied by the time response of the system after a sudden impulse excitation in blade lag direction. Vibration decay ratios are used as a measure for instability. This study is repeated in sweeps over the rotation frequency to visualize the safe margin of frequencies. The resulting changes in fuselage frequencies are determined by a frequency analysis of the time response. They are correlated to frequency margins of the rotor blade regressive lead-lag motion in the non-rotating system $\varsigma_{\text {reg }}$, which is shown in Fig. 3.

The eigenvalues in the non-rotating system are plotted over the rotation frequency. In addition to the collective 


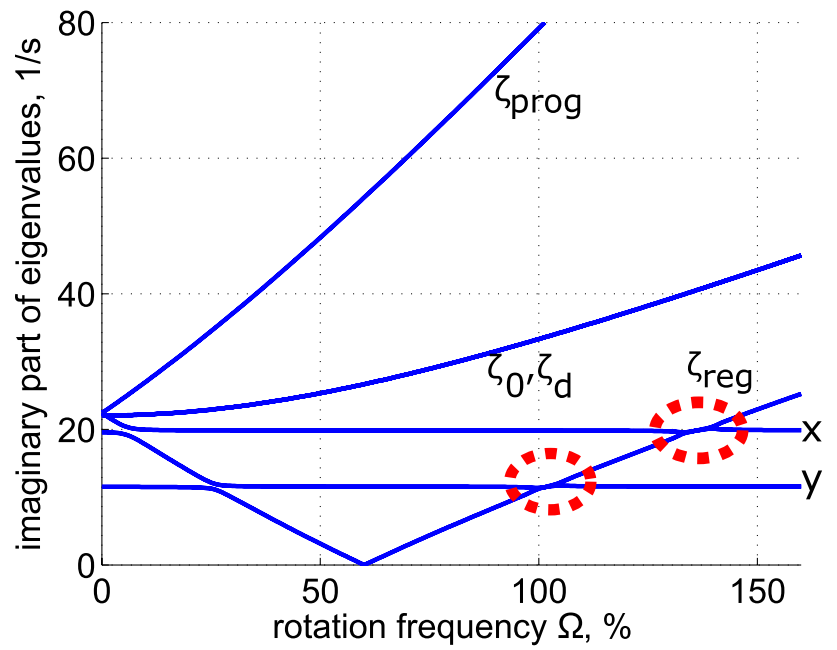

Fig. 3 Eigenvalues in the non-rotating system dependent on the rotation frequency; collective and differential blade motion $\zeta_{0}$ and $\zeta_{d}$; regressive and progressive lead-lag motion $\zeta_{\text {reg }}$ and $\zeta_{\text {prog }}$, hub motion in $x$ and $y$ direction

and differential lead-lag motion $\zeta_{0}$ and $\zeta_{\mathrm{d}}$, the progressive lead-lag motion $\zeta_{\text {prog }}$ and the regressive lead-lag motion $\zeta_{\text {reg }}$ are shown. Moreover, the eigenvalues of the translational hub degrees of freedom in $\mathrm{x}$ - and $\mathrm{y}$-direction are shown. The blade motion must be transformed into the non-rotating frame to show the interaction of the regressive lead-lag and the hub motion. Ground resonance can occur, where the curves of the regressive lead-lag motion and the hub motion cross. These points are highlighted by the red, dotted circles.

The above-mentioned frequency analysis of the time signal serves as a systematic classification of critical landing configurations. In the end, the influence of contact properties like contact location and contact area is varied. The resulting changes in damping behaviour are compared to the reference case of full ground contact. This is done to provide a detailed study of the influence of the skid contact area on the helicopter's stability in ground contact. Aerodynamic forces are neglected for reasons of simplicity, since this work mainly focuses on different approaches for structural modelling. However, it has to be noted that for the given landing scenario, the assumption that aerodynamic forces show negligible influence is not given. In [23], it is shown that dynamic inflow may play an important role in ground-resonance like situations. While out of the scope of this work, it would be interesting to study the relative importance of contact points vs. aerodynamic forces on ground resonance stability. It has to be highlighted that the goal of this investigation is not to accurately remodel ground terrain in detail, but to understand the influence of partial ground contact on resonance stability and to find a usable analysis method for skid contact configurations.

\subsection{Structural model}

The helicopter structure is modelled using the multibodysoftware SIMPACK to allow dynamic studies [10]. The model consist of rotor, airframe, and landing gear, as shown in Fig. 4.

The elasticity of the landing gear dominates the lowfrequency spectrum of the helicopter model. Therefore, the fuselage is modelled as a rigid body. Its mass, inertia, and size are chosen in reference to the BO105 [20] for the direct finite-element landing gear model and in reference to the EC135 for the modal reduced model seen in Fig. 5. The landing gear models will be presented in more detail in the following section. The connection points for the landing gear model are located at the same position as the real landing gear attachments.

The time simulation uses an adapted rigid blade rotor model. Spring elements at the blade-hub connection ensure a lead-lag frequency similar to real rotor blades. However, the damping properties and reference rotation velocity of the rotor model were modified, since the real Bo105 rotor is specifically designed not to be susceptible to ground resonance.

Fig. 4 Helicopter model Bo105

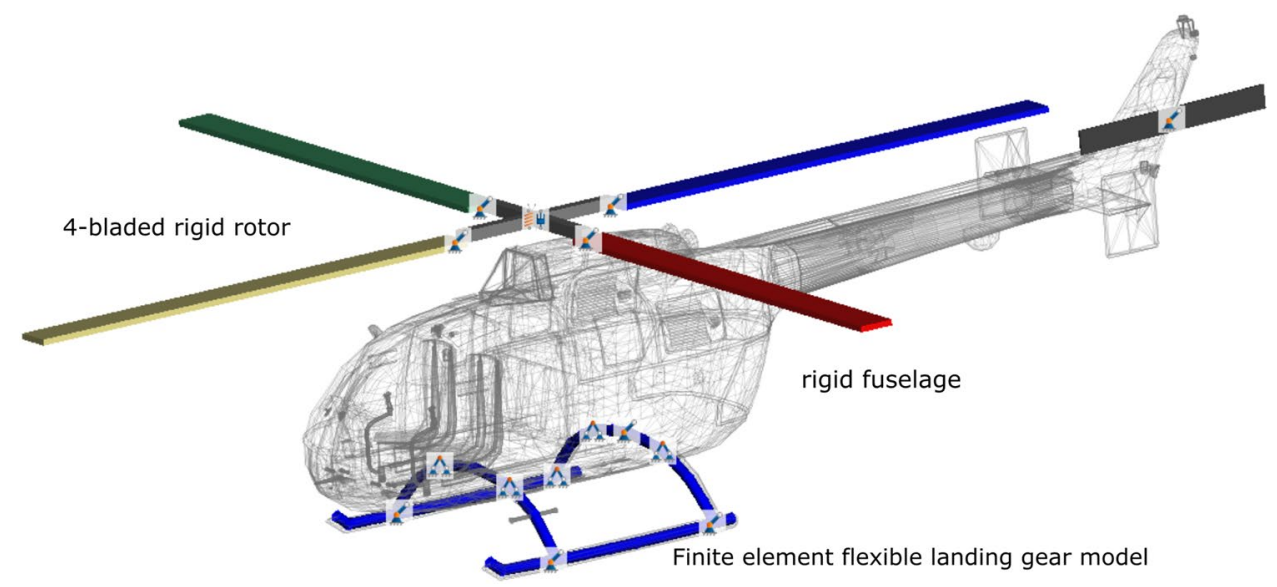


Fig. 5 Helicopter model EC135

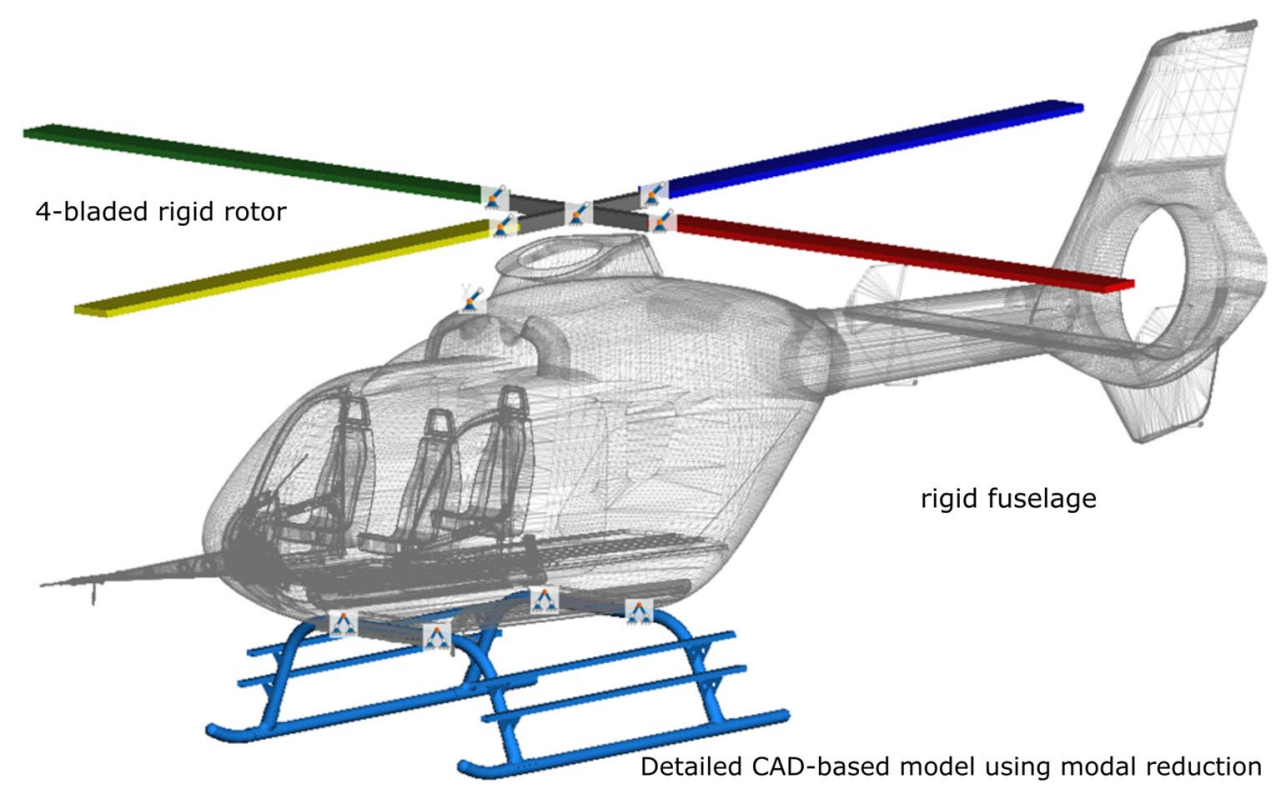

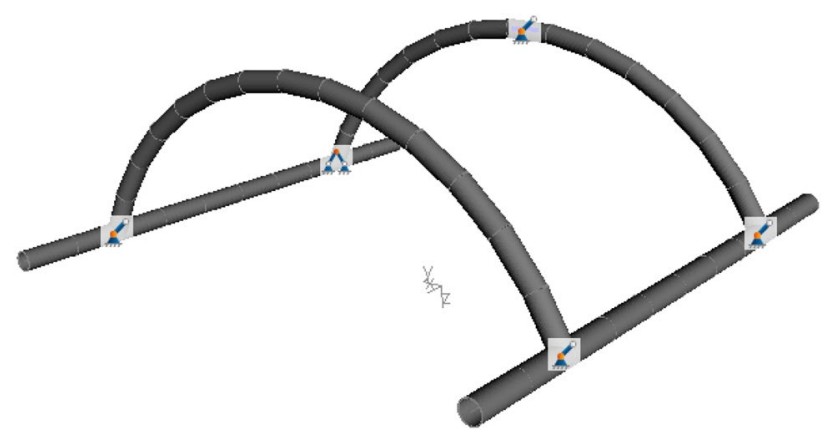

Fig. 6 Elastic landing gear model

The rotor model is used for all landing gear and ground contact models to simplify the post-processing.

\subsection{Landing gear models}

As a first step to study the influence of contact conditions on the ground resonance of helicopters, an elastic landing gear system as illustrated in Fig. 6 was modelled. The landing gear represents an assembly of aluminium tubes. It is modelled as 1D-Euler-Bernoulli beams in the SIMPACK-internal FE-module SIMBEAM. The crosssectional diameters and material properties are based on the Bo105. This model was chosen, because it is simpler than the one of the EC135 and more information was available during the time of this study. Since the behaviour of a skid landing gear is to be studied in general, there is no need for a perfect fit with the real helicopter skid landing gear during the first simulations. This model is used as a first research basis and will be updated and improved continuously. Each skid of the landing gear consists of ten 1D-Euler-Bernoulli beam elements. The rear and front boom are modelled as separate bodies by 14 finite elements. The landing gear is rigidly constrained to the helicopter fuselage.

In addition to the simplified landing gear model in Fig. 6, contact studies are prepared for an EC135 landing gear imported into SIMPACK as a modal reduced flexible model. This FE-MBS coupling allows the simulation of complete mechanical systems. In the MBS analysis, the flexible body's motion is described by a modal representation with considerably small number of modal coordinates in comparison to the large number of nodal coordinates in finite-element programs. This allows to predict the dynamics of a mechanical system with relatively low computational costs. This modal reduction of an FEM structure is the standard approach to implement more detailed models in most multibody dynamic simulations.

To implement the landing gear model of DLR's EC135 Flying Helicopter Simulator (FHS), several processing steps in the finite-element software ANSYS and SIMPACK are necessary. SIMPACK uses flexible body input files (.fbi) to enable the integration of flexible bodies from finite-element codes such as ANSYS.

These files combine information about the original finiteelement mesh and geometry, the boundary conditions, and the representation of the original structure in modal form. The mode shapes and eigenfrequencies are determined by a component mode synthesis (CMS) as described in [24]. The CMS reduces the system matrices to a smaller set of interface degrees of freedom and normal mode generalized coordinates. These information are provided by the finiteelement program ANSYS. 


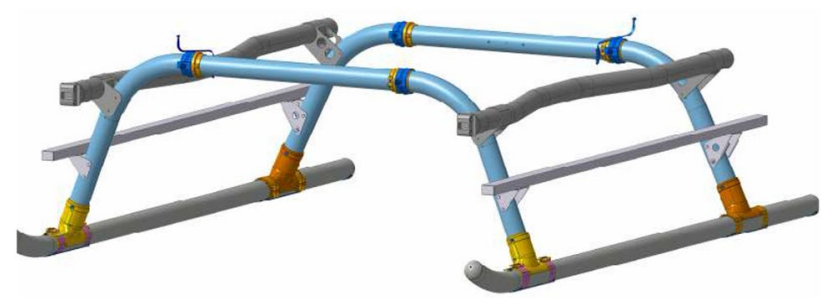

Fig. 7 Original, fully detailed CAD model of the EC135 landing gear

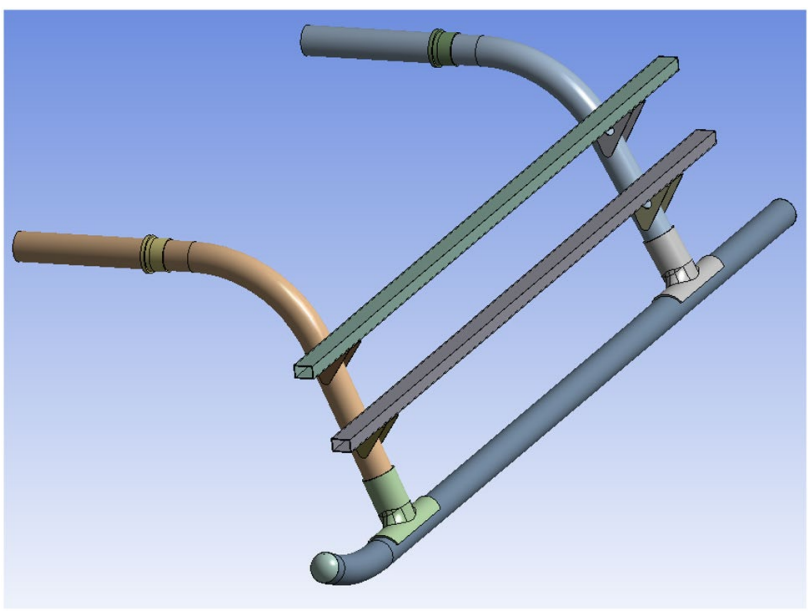

Fig. 8 Simplified geometry

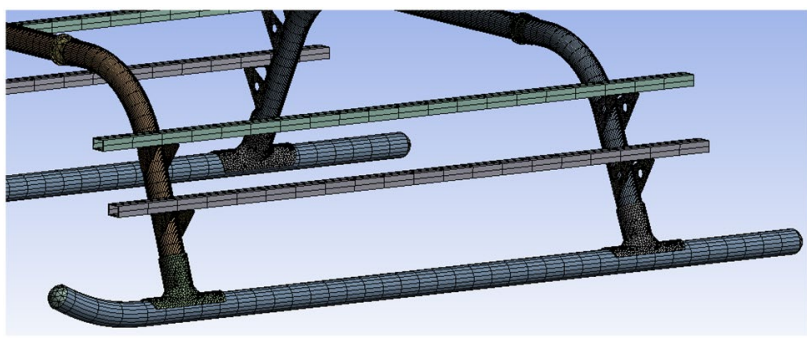

Fig. 9 Mesh visualization

Starting with the original CAD data of the FHS as given in Fig. 7, the geometry complexity was reduced. The CAD was originally created for construction purposes. For a modal analysis, this level of detail only marginally improves the results and would not justify the massive effort to create a suitable mesh. Figure 8 shows the geometry simplification. In ANSYS, geometrical contacts and structural compounds can be modelled by contact elements. However, SIMPACK is not able to process such elements in the generation of the flexible body input files. Therefore, after the initial mesh generation, node merges were used to modify the mesh. The result is visualized in Fig. 9.

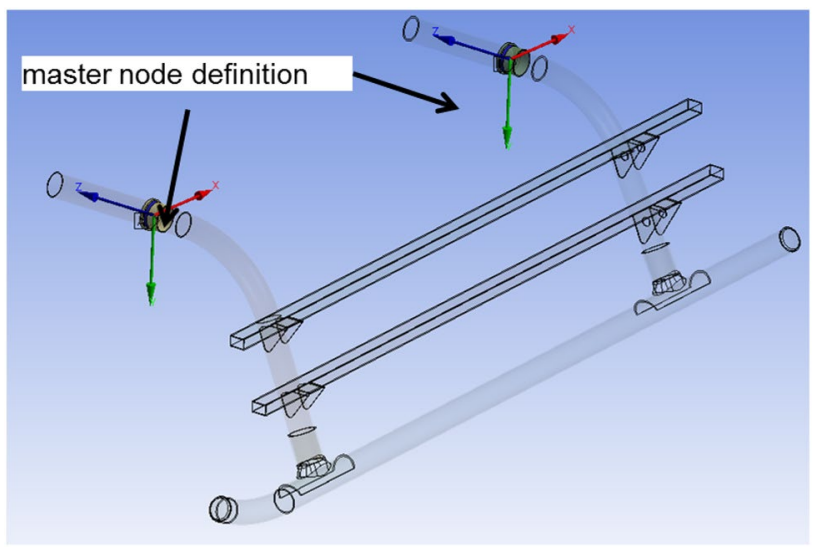

Fig. 10 Landing gear interface for MBS

To provide an interface between the FE structure and the MBS model, so-called " "master nodes"” are explicitly selected during the reduction of the finite-element structure. These nodes are later used as marker position in the MBS simulation. Bearings encompassing the landing gear brackets are defined and shown in Fig. 10. The reference nodes of these bearings are defined as master nodes, because at this position, the landing gear will be attached to the rest of the helicopter structure. Moreover, it has to be ensured that forces and moments acting on the bearing are correctly applied at the attachment marker. During this work, it became apparent that the selection of these "master nodes" is of utmost importance to get correct eigenfrequencies for the landing gear model.

For the CMS the Craig-Bampton method is used, defining the interface as fixed. The reduced model, sometimes called superelement, considers the first 30 modes. The result file (.sub) containing the superelement, the result file of the recovery matrix (.tcms) containing the data recovery (nodal DOF solution) for all nodes and the FE geometry file (.cdb) are imported into SIMPACK and the ffbi-file is generated.

Finally, the resulting model in SIMPACK gives a detailed representation of the original flexible model. The predefined interface nodes allow attaching SIMPACK contact force elements like 3D contact element which depend on the exact geometrical deformation of the given model. It is, therefore, essential to include such a model in the study of operational contacts.

\subsection{Contact simulation}

\subsubsection{Spring-damper elements}

In previous works, dedicated grids of the skids were clamped to the ground [2]. However, this contact simulation has the disadvantage of unrealistic forces and moments that can build up in the contact due to constraint degrees of 
freedom. In flight tests, similar contact conditions can only be achieved by dedicated pilot inputs forcing the helicopter into ground contact. To find alternatives to this approach, two types of contact representation were tested in the SIMPACK model. The SIMPACK force element "Unilateral Spring-Damper" is able to define the vertical (z-component) of the contact. It also allows to specify the area in which the contact laws are defined and can be used with friction models like stick-slip friction. This type is used for the first time simulations.

The second contact type is the polygonal contact method (PCM). This force element is able to detect and model 3D multi-point contacts. It bases the calculation of contact forces on the parts' geometry, allowing the full description of skid contact in vertical and horizontal directions. This gives a more realistic representation of real world contacts. The contact type bases the calculation of the contact force on the model geometry and its material properties. This contact type is tested using the flexible modal EC135 landing gear model described in Sect. 3.2. Additionally, this contact allows a more detailed study of soft ground conditions for future studies, since it allows flexible-flexible multi-point contacts. Using this contact type with flexible bodies, one has to consider that the contact definition itself allows to specify an elasticity. To avoid a series connection of the contact elasticity and the one of the landing gear model itself, the first one is set to zero. For the ground representation, the material parameters of concrete were used, including the coefficient of friction. A representation of the model setup is shown in Fig. 11.

The model is connected to the ground via the landing gear skids and its variable hatched marked contact areas, as shown in Fig. 11. The size of these contact areas is varied, ranging from full contact, representing the classic configuration, to partial ground contact according to the Donham test cases described in Fig. 2. The early studies described in this work use four contact patches of equal size, starting at

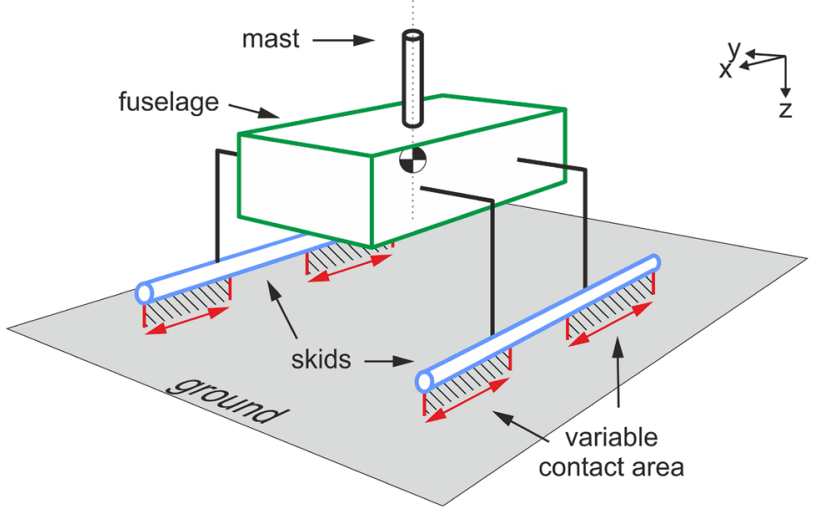

Fig. 11 Visualization of principle of contact area variation both ends of the skid as visualized in Fig. 11. In future studies, asymmetrical configurations will be used, as well. The contact forces are applied at the nodes of the 1D-Euler-Bernoulli beams which is shown in Fig. 12. Additional friction elements act directly on these force elements, which are in the foreground of Fig. 12. The contact elements are only applied to those regions of the skid which have contact with the ground represented as the ocker, rectangular areas in Fig. 12.

\subsubsection{PCM-contact elements}

The polygonal contact elements (PCM elements) in SIMPACK bases body surfaces on polygon meshes derived from the underlying FE mesh or attached CAD files. Contact force determination relies on the elastic foundation model. Thus, for usage in a simulation, one needs the structural and geometrical representation. The usage of PCM elements allows multiple bordered contact patches and conforming contacts [25]. Moreover, this contact type was chosen due to its promised robustness for complex geometries as they can appear for uneven ground structures.

The contact simulation is calculated in three steps. In the first step, the collision detection, a geometric algorithm based on the polygonal meshes of the geometrical representation is used to determine if, and in which areas, a contact occurs. This approach is suitable, because the geometrical representation is often finer than any finite-element mesh used for the structural simulation. It is not simplified or cropped to reduce computation cost or used for other calculations. Afterwards, the contact is modelled. The PCM elements construct the intersecting areas and discretize the contact patches, as given for example in Fig. 13. Based on these contact patches, the third step is performed. The resulting forces and torques of all contact elements are calculated. The PCM elements apply regularized coulomb friction forces in each contacting polygon and assign a normal stiffness for each surface of a polygon. This stiffness depends linearly on the polygon area.

The contact determination and calculation is handled during simulation in this step-wise process. It allows the modelling of dynamic contacts with multiple contact points

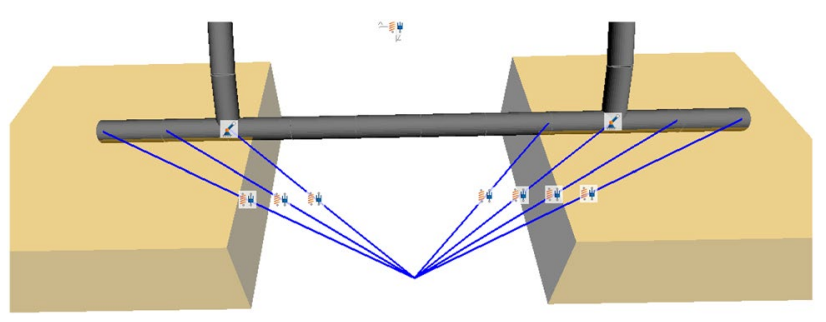

Fig. 12 SIMPACK contact element applied to landing gear 


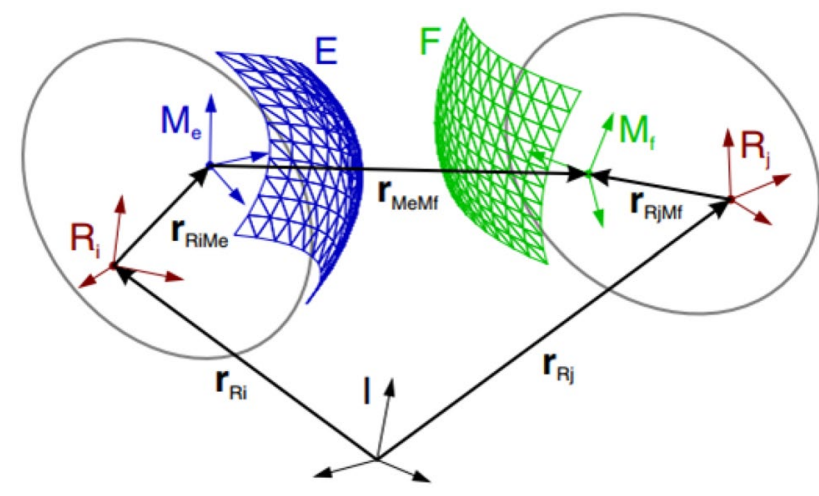

Fig. 13 Intersecting area of the surfaces and corresponding contact patches

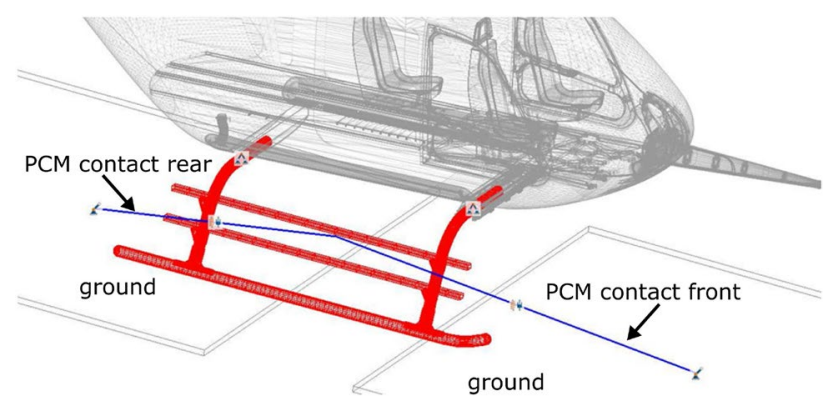

Fig. 14 PCM contact of the EC135 landing gear

without complex a priori consideration, resulting in a straight-forward model setup as seen in Fig. 14.

\section{Results and discussion}

As a first preliminary analysis to verify the MBS approach for ground resonance studies, a Coleman-Feingold model was implemented in SIMPACK. This model consists of four rigid rotor blades, which are elastically attached to a centre mass. The system encompasses the lead-lag degree of freedom for the blades and the translational ones for the mass. As described in Section 3, the blade motion is transformed into the non-rotating system and an eigenvalue analysis is performed. Plotting the real part of the degrees of freedom in Fig. 15 highlights the rotation frequencies where ground resonance occurs. In resonance condition, the real parts which correlated to the system damping drastically increases up into positives values indicating instability. The red dotted line shows the pure analytical solution used as a reference; the black solid line shows the results of the Coleman-Feingold model.

To test the approach described in Sect. 3, time simulations for the first SIMPACK model with two spring-damper

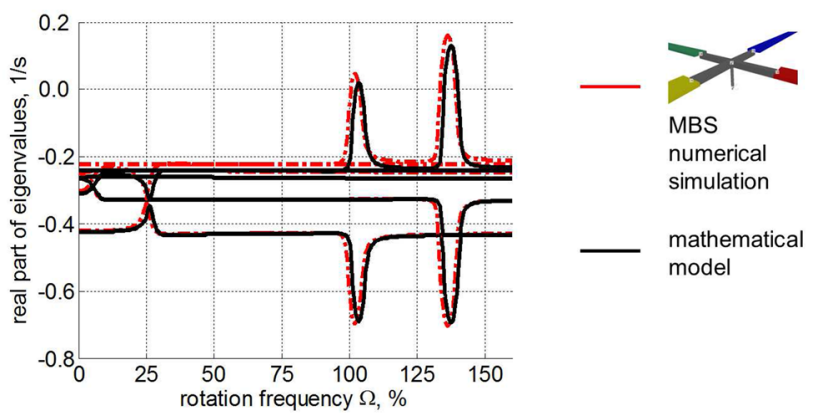

Fig. 15 Hub motion eigenvalues in $x$ - and $y$-direction

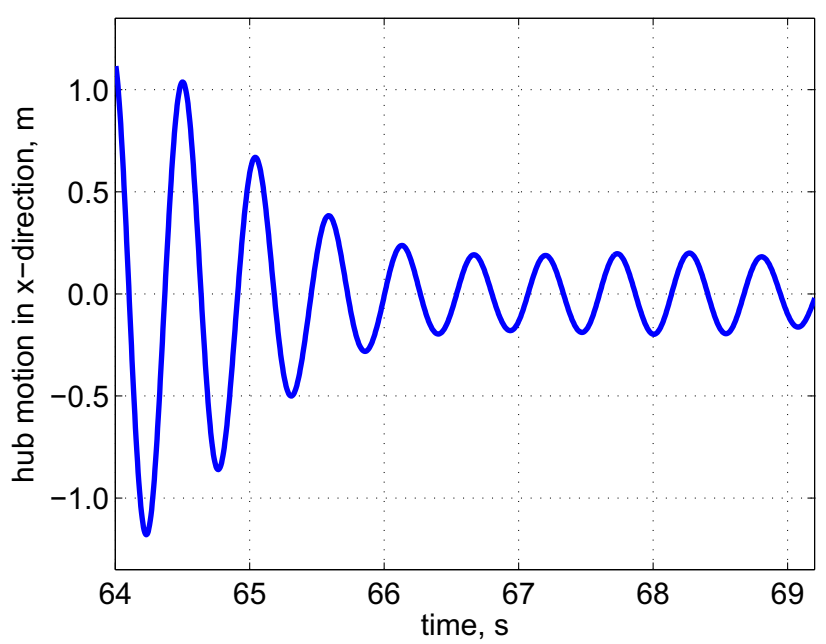

Fig. 16 Filtered sensor measurement of longitudinal hub motion

elements as landing gear representations were performed. The filtered time signal of a sensor at the hub of this model is visualized in Fig. 16. A Butterworth filter of order 4 was used to eliminate high-frequency components and to reduce numerical noise. The signal plot starts after a sudden impulse excitation at $64 \mathrm{~s}$.

For a large set of test cases, the decay ratio can be calculated automatically by measuring the local peaks and their progression in time. This indicates whether a periodic solution, decreasing or an increasing oscillation occurs. In the presented case, a periodic time response with decreasing amplitude can be observed. However, after approximately $66 \mathrm{~s}$, a periodic time response with constant amplitude remains. These remaining non-subsiding oscillations are typical for non-linear systems. Thus, the non-linear dynamic behaviour due to partial ground contact can be observed in the time signal of the simplified SIMPACK model, although some signal processing is necessary. The results of this MBS model correlate with the results presented in [20].

The approach of Sect. 3 is applied to the SIMPACK landing gear model of Fig. 4 with full ground contact. Model mass and the landing gear stiffness were chosen in a way 


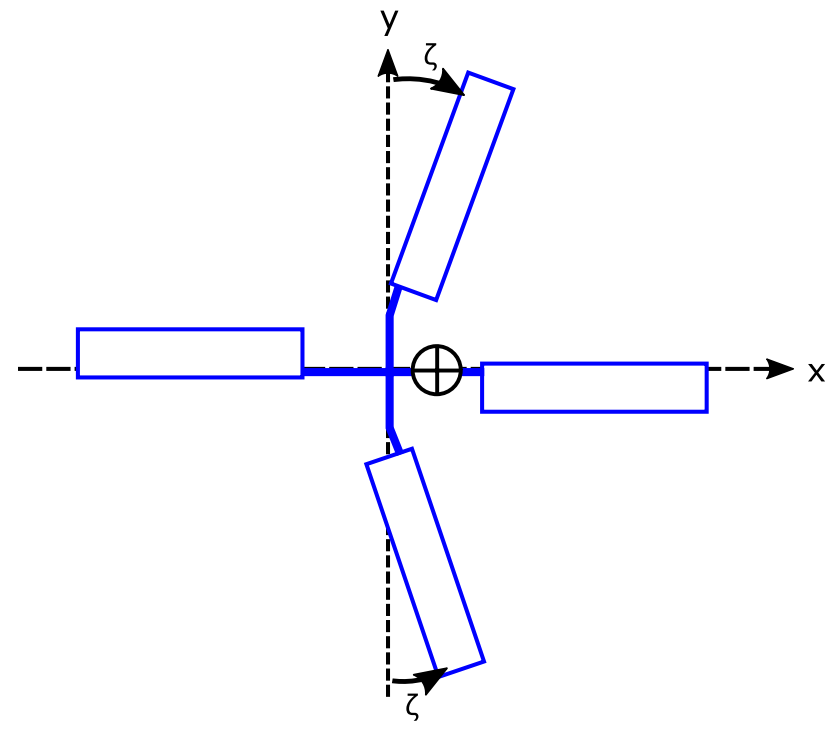

Fig. 17 Excitation of rotor system

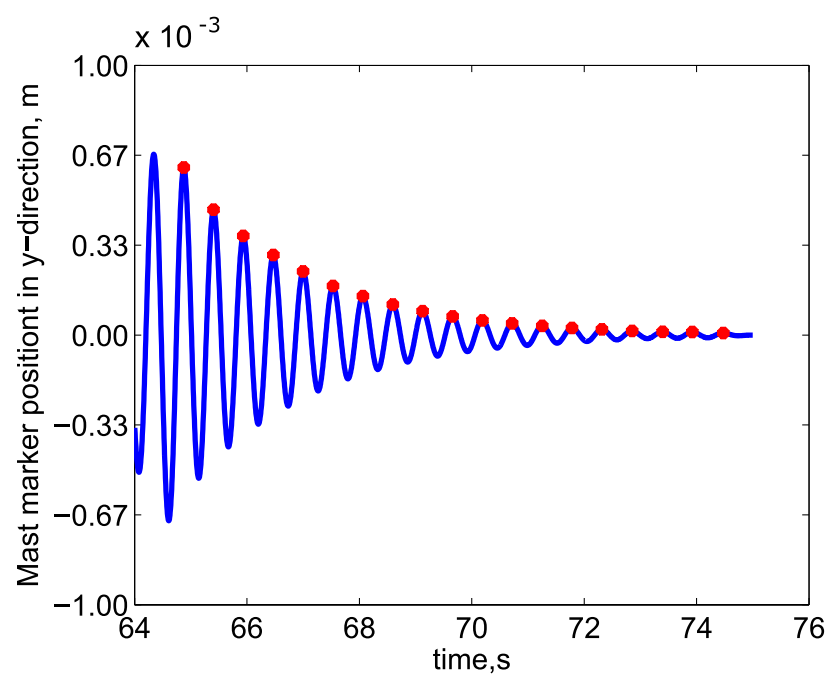

Fig. 18 Filtered signal of hub motion in $y$-direction to give similar frequencies as in the simplified Coleman model. Contact patches, as illustrated in Fig. 11, stretch the full length of the skids on both sides. The model is time integrated for $60 \mathrm{~s}$ to allow the ground contact to "settle in". Assuming enough lead-lag damping, the helicopter model should not get into resonance without artificial excitation at $62 \mathrm{~s}$. A sudden excitation of $1000 \mathrm{~N}$ in the chord direction of the first and third blades is applied, as shown in Fig. 17. A direct response of the excitation impulse is shown in Fig. 18. The system reaction is measured for a rotation frequency sweep from 0.1 to 1.8 times the reference rotation frequency of $44.4 \mathrm{rad} / \mathrm{s}$. The results for the test case at $14.2 \mathrm{rad} / \mathrm{s}$ are presented as an example. Figure 18 shows the filtered signal of the position marker at the hub in $y$-direction, correlating to the models' roll movement.

The signal is filtered using a Butterworth filter of fourth order as described above. The selected bandwidth is chosen in reference to the lowest landing gear eigenfrequencies eliminating higher frequency noise. From this filtered signal, a subset of peaks was selected to determine the decay ratio using the logarithmic decrement. It has to be mentioned that the logarithmic decrement is a measurement parameter often used to calculate the damping coefficient of linear systems. Here, it is used in a general sense to visualize the systems damping behaviour. It is plotted over the rotation frequency, as shown in Fig. 19.

For this contact configuration, the presented approach delivers the results comparable to the analytic result. Figure 19 shows the calculation results as the solid blue line. A classical, analytical Coleman and Feingold model was used to calculate the reference results, which are shown as the dotted black line. The decrease at around $108 \%$ of the reference frequency and the increase at around $142 \%$ match the results of the classical model. The borders of the damping change fit the expectations. However, the results of the SIMPACK model show a continuous course between 110 and $130 \%$ of the reference rotation frequency. This could be due to an insufficient number of calculation steps, leading
Fig. 19 Visualization of equivalent logarithmic decrement

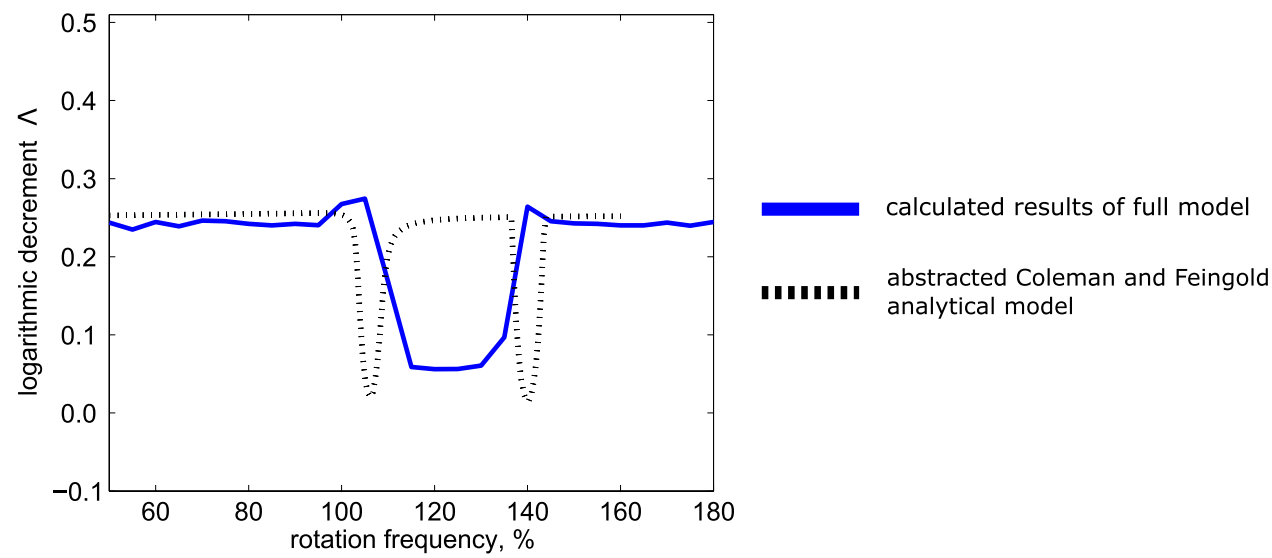


to a low resolution of the results. The quality of the results has to be improved in the future to meet scientific standards. Therefore, additional tests are necessary.

\subsection{Advanced models with PCM contact}

Two advanced model variations were created in this study. Both models use PCM contact elements. Spring-damper elements only give punctual influence on the landing gear model. The models with PCM contact are:

- a version of the Bo105 landing gear, as seen in Fig. 20

- the EC-135 landing gear of the DLRs research helicopter FHS in Fig. 21.

The PCM model is intended to determine a detailed 3D contact based on the geometry of the model and to calculate the contact forces based on the structural finite-element model or modal reduced model data.

The contact is established between the ground areas and landing gears geometry representation. The latter is connected to the rigid fuselage of a Bo105 and EC135, respectively. For the EC135 models, the contact configurations are visualized in Fig. 21.

For simplicity and easier comparison of the results, the same rotor model is used for all landing gear variations. Since landing gears and rotor models are usually configured to avoid the occurrence of ground resonance, the rotor system would have to be modified anyway. In Fig. 22, the result of the MBS transformation over the rotational frequency of the standalone rotor is shown. The red lines show the eigenfrequency of the standalone EC135 landing gear model attached to the fuselage for full contact. The crossing of the landing gear frequency and the regressive lead-lag eigenfrequency marks the region of interest for ground resonance.

\subsection{Time signal analysis}

First results of the time signal calculations are shown for the EC135 landing gear. Two contact configurations are chosen

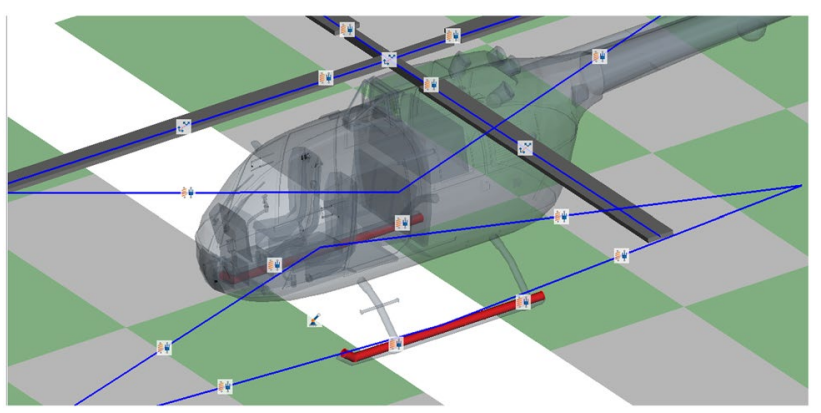

Fig. 20 Bo105 high landing gear with four-patch PCM contact

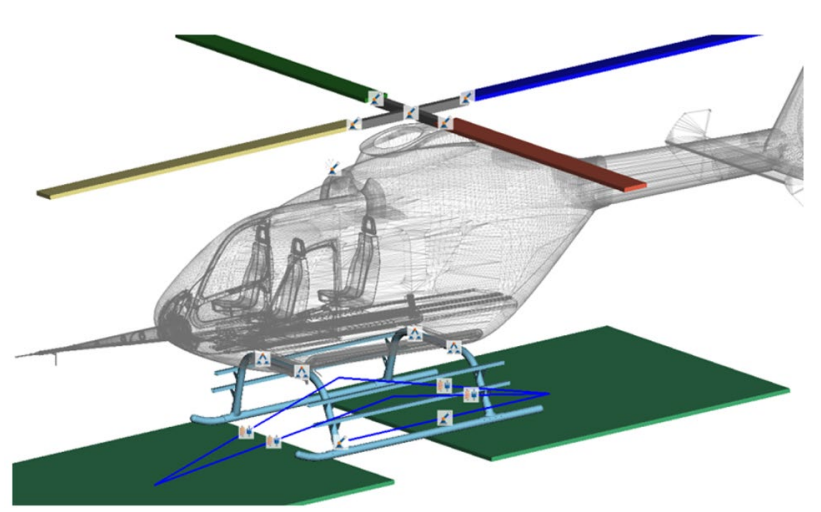

Fig. 21 Four-patch PCM contact of the EC135 landing gear

to elucidate the PCM contact. First, the four-patch configuration, as shown in Fig. 21, simulating a landing in a pit and second, the same model in full contact.

The models were "set on the ground" and time integration continued till remaining vibrations due to the landing contact subsided. Then, the helicopter model is excited by sudden short force impulses at the first and third blade tip, deliberately causing an imbalance of the rotor. This excitation occurs at $20 \mathrm{~s}$.

Figure 23 shows the time signal of the PCM contact at the left landing gear side for 19-24 s. As can be seen, the contact captures the forces in $x$-, $y$-, and $z$-direction. The small vibrations prior to the $20 \mathrm{~s}$ excitation are caused by the main rotor angle. Whereas after $20 \mathrm{~s}$, the reaction due to the excitation is clearly visible. The four-patch contact shows a higher immediately peak reaction to the excitation. This indicates that while the initial effect is more severe for the four-patch contact, damping effects seem to be more significant. However, it has to be said, that if this is due to

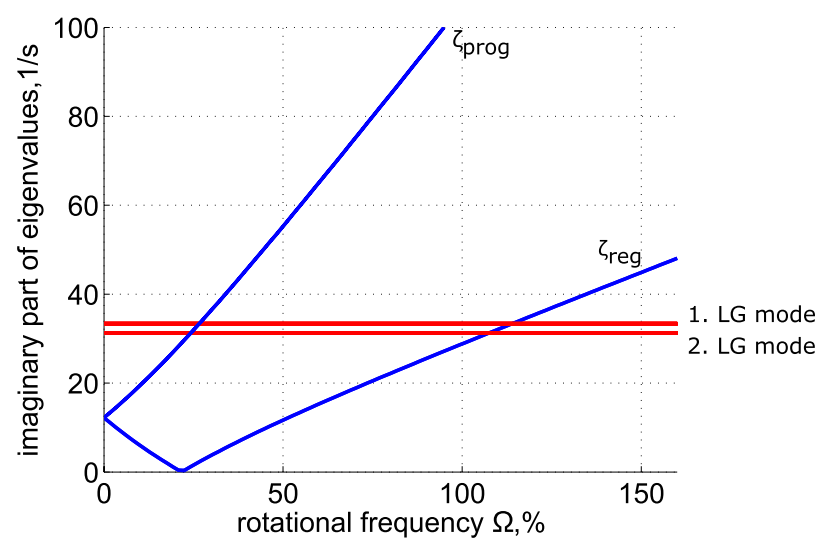

Fig. 22 Progressive and regressive frequency of standalone rotor and first modes of standalone EC135-fuselage-landing-gear-model 


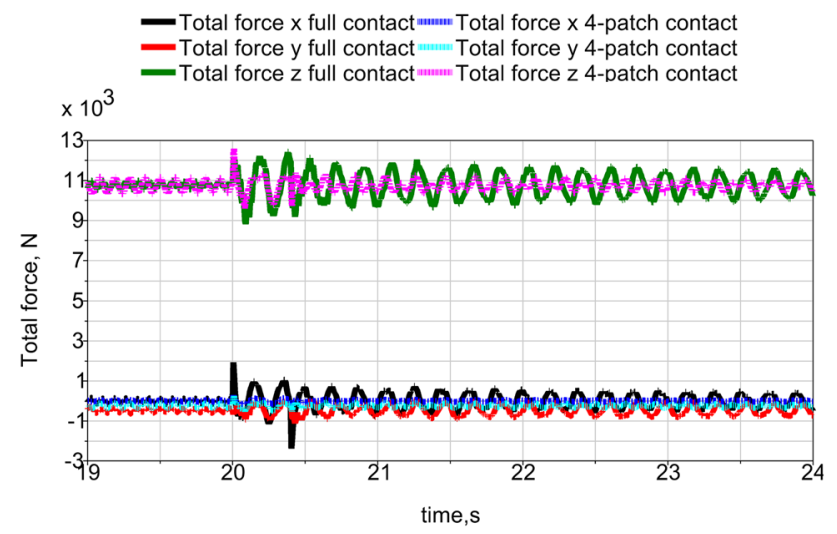

Fig. 23 PCM contact forces for four-patch and full contact

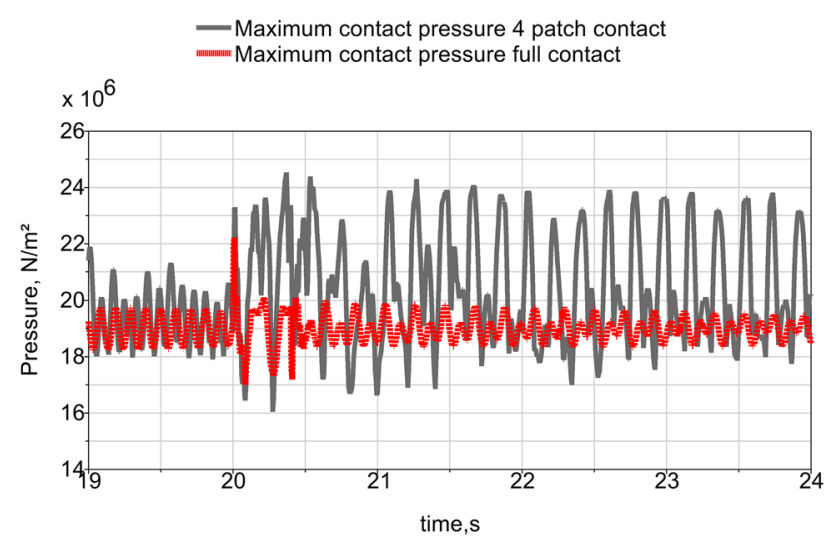

Fig. 24 PCM maximum pressure contact for four-patch and full contact

the chosen parameters or due to modelling choices is subject of ongoing efforts.

Figure 24 shows the maximum pressure contact for the different contact configurations. It is interesting to note that the four-patch contact does not change significantly after the excitation, although the excitation peak at $20 \mathrm{~s}$ is clearly visible. This behaviour is unexpected and contradicts basic physical first intuitions, clearly indicating the necessity of additional model tests.

Both landing gears stay in a stable configuration, although some oscillations remain. To test how the PCM contact behaves for an unstable configuration, the main rotor was modified in a way which causes ground resonance. The reference rotor frequency was increased to $67 \mathrm{rad} / \mathrm{s}$ and the lead-lag damping was reduced to $20 \%$ of its original value. The Bo105 high landing gear model with PCM contact was used. For the tests, the rotation frequency was chosen to be in ground resonance conditions. The corresponding frequencies can be seen in Fig. 25. It has to be mentioned that the rotor model modifications used in these test cases was

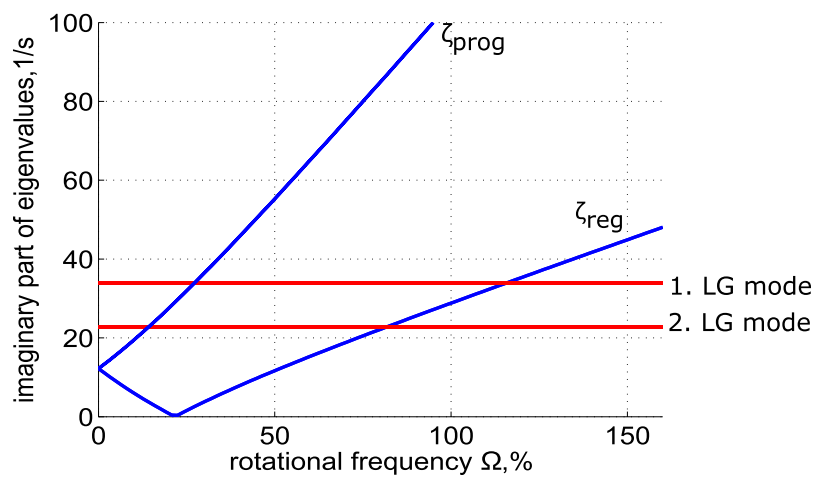

Fig. 25 Progressive and regressive frequency of modified rotor and first modes of Bo105-fuselage-landing-gear-model

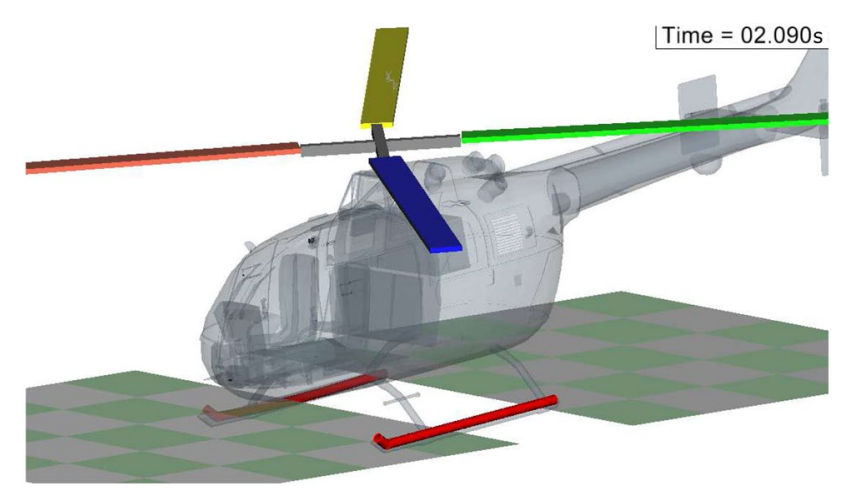

Fig. 26 Ground resonance for landing in pit

adapted based on the assumption of an isolated rotor. If the configuration with contact at the front and rear side of a skid is chosen, the simulation shows an instable behaviour as can be seen in Fig. 26.

It shows the helicopter in ground resonance $2 \mathrm{~s}$ after excitation. The typical blade position causing a displacement of rotation axis and centre of gravity of the rotor are clearly visible. The times of ground contact can be seen in the time signal of the fuselage roll angle in Fig. 27. These results confirmed, that the PCM contact is in principle usable for ground resonance studies.

Eigenfrequencies of the EC135 landing gear, shown in Fig. 22, are much higher than anticipated. To review the generation of the flexible landing gear of the FHS and its usability in SIMPACK, the eigenfrequencies of the modal reduced model were compared to the one with an elastic bearing with a base stiffness of $3 \mathrm{e} 08 \mathrm{~N} / \mathrm{m}^{3}$ at the landing gear attachment points. The eigenfrequencies in Table 1 show a significant difference between these two types of attachment. The relative difference of the elastic attachment is given with reference to the fixed one. For reasons of model simplification, a fixed attachment is chosen for all landing 


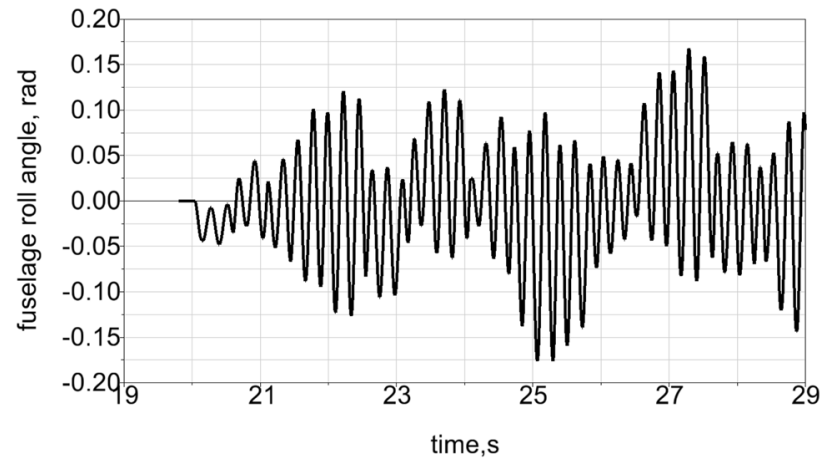

Fig. 27 Roll angle of fuselage and PCM contact in ground resonance

Table 1 Eigenfrequencies of FHS landing gear modes for fixed boundary conditions

\begin{tabular}{lllll}
\hline Modes & $\begin{array}{l}\text { Fixed } \\
\text { attachment } \\
(\mathrm{Hz})\end{array}$ & $\begin{array}{l}\text { Elastic } \\
\text { attachment } \\
(\mathrm{Hz})\end{array}$ & $\begin{array}{l}\text { Absolute } \\
\text { difference } \\
(\mathrm{Hz})\end{array}$ & Relative difference \\
\hline 1 & 18.818 & 14.810 & 4.008 & -0.213 \\
2 & 31.171 & 24.201 & 6.970 & -0.224 \\
3 & 32.045 & 26.628 & 5.417 & -0.169 \\
4 & 33.860 & 53.819 & 19.959 & +0.589 \\
5 & 35.764 & 59.856 & 24.092 & +0.674 \\
6 & 58.480 & 60.714 & 2.234 & +0.038 \\
7 & 62.454 & 69.958 & 7.504 & +0.120 \\
8 & 70.166 & 74.136 & 3.970 & +0.057 \\
9 & 72.956 & 78.998 & 6.042 & +0.083 \\
10 & 75.561 & 82.237 & 6.676 & +0.088 \\
\hline
\end{tabular}

gear models in this work. Therefore, this difference has to be kept in mind for all simulation results.

\section{Conclusion}

The simulation models and results in this paper represent the current status of the ongoing study on the influence of partial ground contact on ground resonance stability. They are a work in progress and have to be evaluated as such. In this work, a ground resonance test environment was created. It encompasses 3D helicopter models with flexible landing gear models using direct finite-element models and models, which apply modal reduction to embed CAD-derived landing gear models in multibody simulation. It was shown that for the modal reduction approach, a special attention has to be given to the landing gears attachment to the fuselage. The selection of these "master nodes" is imperative for correct eigenfrequencies and bearing loads. First analyses are conducted delivering correct results for the classic Coleman and Feingold model and the simplified non-linear model in SIMPACK. Verified simulation of non-linear dynamic behaviour encompasses typical non-linear effects like limit cycles. Routines for the stability analysis of non-linear systems, based on the measurement of time signals after sudden excitation, are implemented. This includes signal postprocessing like filtering of the time signals. These routines are used for the full 3D models, for which several methods to model 3D multi-point contact and friction were tested. For the finite-element landing gear model in full contact and with spring-damper elements, the analysis method produces reasonable results. However, these test cases illuminate the difficulties of studying the non-linear contact conditions. The selection of the filter parameters, especially the selected bandwidth, showed a significant influence on the results. The extension of the described analysis methods to these landing conditions is the focus of current efforts. There is, however, a need for a more sophisticated analysis method.

In addition to multi-directional spring-damper elements, polygonal contact elements (PCMs) were used for contact simulation. These contact elements allow timevariant contact points and consider the change of contact conditions in partial ground contact. In helicopter models and ground resonance studies, this allows the study of more exotic, that means operational-based contact conditions.

The study of the effects of partial ground contact showed the signs of two counteracting effects. On one hand, the reduction of restoring forces should lead to more unstable conditions according to the current literature. On the other hand, energy dissipation show a larger influence on the system stability behaviour after sudden disturbance. Especially for landing scenarios on soft-terrain like sand or gravel, the second effect is of major interest. To investigate these effects and to further validate the usability of PCM elements for ground resonance analysis, additional tests are necessary. The first and early test in this paper only shows that the PCN contact can be used in principle for this purpose.

But more importantly, the current work represents the framework for these tests. The models created for this study are the basis for further investigation of this contact type and extensive parameter studies of ground resonance.

Acknowledgements Open Access funding provided by Projekt DEAL.

Open Access This article is licensed under a Creative Commons Attribution 4.0 International License, which permits use, sharing, adaptation, distribution and reproduction in any medium or format, as long as you give appropriate credit to the original author(s) and the source, provide a link to the Creative Commons licence, and indicate if changes were made. The images or other third party material in this article are included in the article's Creative Commons licence, unless indicated otherwise in a credit line to the material. If material is not included in the article's Creative Commons licence and your intended use is not permitted by statutory regulation or exceeds the permitted use, you will need to obtain permission directly from the copyright holder. To view a copy of this licence, visit http://creativecommons.org/licenses/by/4.0/. 


\section{References}

1. Johnson, W.: Helicopter Theory, pp. 668-693. Princeton University Press, Princeton (1980)

2. Dieterich, O., Houg, W.: Ground resonance investigation of slope landing operating conditions. In: American Helicopter Society Specialists' Conference on Aeromechanics Design for Vertical Lift, San Francisco (2016)

3. Coleman, R.P., Feingold, A.M.: Theory of Self-Excited Mechanical Oscillations of Helicopter Rotors with Hinged Blades. NACA TR 1351, U.S. Government Printing Office, Washington DC (1957)

4. Donham, R.E., Cardinale, S.V., Sachs, I.B.: Ground and air resonance characteristics of a soft in-plane rigid-rotor system. J. Am. Helicopter Soc. 14(4) (1969)

5. Bousman, W., Sharpe, D., Ormiston, R.: An experimental study of techniques for increasing the lead-lag damping of soft in-plane hinge-less rotors. American Helicopter Society 32nd Annual Forum, Washington DC (1976)

6. Hodges, D.H.: An aeromechanical stability analysis for bearingless rotor helicopters. J. Am. Helicopter Soc. 24(1) (1979)

7. Kunz, D.: Nonlinear analysis of helicopter ground resonance. Real World Appl. 3(3) (2002)

8. Yang, M., Chopra, I.: Vibration prediction for a rotor system with faults using a coupled rotor-fuselage model. J. Aircr. 41(2) (2004)

9. Eckert, B.: Analytical and Numerical Ground Resonance Analysis of a Conventionally Articulted Main Rotor Helicopter. Stellenbosch University, South-Africa (2007)

10. Gualdi, S., Masarati, P., Morandini, M., Ghiringhelli, G.L.: A multibody approach to the analysis of helicopter-terrain interaction. In: 28th European Rotorcraft Forum, Bristol (2002)

11. Rezaeian, A.: Helicopter ground resonance analysis using multibody dynamics. In: 36th European Rotorcraft Forum (2010)

12. Mohan, R., Gaonkar, G.: A unified assessment of fast floquet, generalized floquet, and periodic eigenvector methods for rotorcraft stability predictions. J. Am. Helicopter Soc. 58(4) (2013)

13. Attilio, C.: Complex modes in ground resonance stability analysis. European Rotorcraft Forum 2000, Issue 63

14. Nair, S., Mohan, R.: Detection and control of ground resonance using phase of fuselage attitude rates. European Rotorcraft Forum 2016, Issue 145
15. Tamer, A., Maserati, P.: Helicopter rotor aeroelastic stability evaluation using Lyapunov exponents. European Rotorcraft Forum 2014

16. Avanzini, G., de Matteis, G.: Effects of nonlinearities on ground resonance instability. European Rotorcraft Forum 2008 (2008)

17. Kaan, S., Kargun, V., Zengin, U.: A Generic Ground Dynamics Model for Slope Landing Analysis. Turkish Aerospace Industries, Anakara (2016)

18. van der Wall, B.G.: Grundlagen der Hubschrauber-Aerodynamik. Springer, Berlin, ISBN: 978-3-662-44399-6 (2015)

19. Tang, D.M., Dowell, E.H.: Effects of nonlinear damping in landing gear on helicopter limit cycle response in ground resonance. In: Second Decennial Specialists' Meeting on Rotorcraft Dynamics, NASA Ames Research Center, Moffett Filed (1984)

20. Kessler, Ch.: Aktive Steuerung aeromechanischer Instabilitäten bei Hubschraubern mit Übergang vom Boden in die Luft. Technische Universität Braunschweig, Dissertation TU Braunschweig (1996)

21. Kessler, Ch., Reichert, G.: Active control of ground and air resonance including transition from ground to air. In: 20th European Rotorcraft Forum, Amsterdam (1994)

22. Yin, S.K., Hohenemser, K.: The method of multiblade coordinates in the linear analysis of lifting rotor dynamic stability and gust response at high advance ratio. American Helicopter Society 27th Annual Forum, Washington DC (1971)

23. Johnson, W.: Influence of unsteady aerodynamics on hingeless rotor ground resonance. J. Aircr. 19(8), 668-673 (1982)

24. Craig, R., Bampton, M.: Coupling of substructures for dynamic analysis. AIAA J. American Institute of Aeronautics and Astronautics (1968)

25. Hippmann, G.: An algorithm for compliant contact between complexly shaped surfaces in multibody dynamics. Multibody Dynamics IDMEC/IST, Lisbon (2003)

26. Ewald, J.: Untersuchung zur aeromechanischen Stabilität des Hubschraubers. ZLR-Forschungsbericht 91-05, Technische Universität Braunschweig (1991)

Publisher's Note Springer Nature remains neutral with regard to jurisdictional claims in published maps and institutional affiliations. 